\title{
Modelling behaviour of a partially loaded road tanker with agro-food liquids during the breaking manoeuver
}

\author{
Gabriela Milian ${ }^{1, *}$, Sorin-Ştefan Biriş ${ }^{1}$, and George Ipate $^{1}$ \\ ${ }^{1}$ University "Politehnica” Bucharest, 313, Splaiul Independentei, 060042, Romania
}

\begin{abstract}
Longitudinal and lateral liquid sloshing in a partially filled tanker affect the braking performance of the tankers. The movement during braking of the liquid load is determined by the change in the position of the centre of gravity of the load inside the vehicle. Becoming an undesirable phenomenon when analyzing the performance of the vehicle braking manoeuver. In this paper modelling of the behaviour of the cross-section circular tank with baffles, partially filled with liquid agro-food products, was performed, which performs a braking manoeuver. Two different fluids have been used to simulate the sloshing effect of agro-food liquid cargo and study the behaviour of the tank. In to order generate the geometric model of the tank was done by using SolidWorks, and simulating the behaviour of the tank and cargo with agro-food products during the ANSYS-CFX braking manoeuver. A sequence of numerical experiments has been carried out to estimate the pressure developed over the tanker wall and the free surface displacement of the fluids for different fill levels. Simulations with the two liquids and the results obtained were compared to be able to analyze the behaviour of the tank partially filled into a braking manoeuver.
\end{abstract}

Keywords: sloshing liquid, braking, agro-food liquid, ANSYS, baffles

\section{Introduction}

Sloshing has been described by the researchers as different: as a dynamic load acting on the tanker structure due to the movement of a fluid with a limited free surface inside the tank [1], or a strong movement of fluid from a moving tank [9]. The movement during braking of the liquid load is determined by the change in the position of the centre of gravity of the load inside the vehicle. In modeling the behavior of tankers, account is also taken of tank geometry; fill level; lateral and longitudinal force during typical maneuvers and dynamic interactions of the liquid structure [2]. For example, the ADR standard [3] specifies the detailed requirements for different tankers, as the structure shall of the tanks must resist an acceleration of $2 \mathrm{~g}$ in vertical and longitudinal direction and $1 \mathrm{~g}$ in lateral direction.

Over the years, the problem of partially filled tanker behavior with liquid products inside of which sloshing occurs has led of researchers to use different study methods and techniques. Salem et al. (2000) demonstrated that partially filled tankers undergoing turns or lane change maneuvers have a lower rollover threshold than any other type of vehicle [4].

* Corresponding author: gabi_isb@yahoo.com 
Akyildiz et al.(2006) have been found by numerical and experimental research pressure variations and three-dimensional effects on liquid sloshing loads in a moving partially filled rectangular tank [9]. Liu et al. (2008) accomplished numerical model to study threedimensional (3D) liquid sloshing in a tank with baffles [8]. Godderidge et al (2012) investigated using CFD code to study sway-induced sloshing flow in rectangular tank. They conducted a comparative study between homogeneous and inhomogeneous multiphase model for fluid density and viscosity. After a comparison between the results obtained numerically and experimentally shows that the homogeneous model gives less accurate result for peak pressure up to $50 \%$ as compared to inhomogeneous multiphase model [4]. Sarabi et al. (2012) studied the effect of ground motion on sloshing inside rectangular tank, used CFD simulation tool Open FOAM (Open Filed Operation and Manipulation). Results shows that the intensity of sloshing and pressure loads depend on the tank geometry, fill level, amplitude, frequency of excitation [4]. Di Nardo et al. (2012) studied the behavior of liquid fuel storage tank of cylindrical shape when subjected to an earthquake. They used VOF technique to assure an accurate description different filling levels, for 7 different acceleration inputs. Results shows that the sloshing of fluid depends on excitation frequency and filling levels [4]. Zheng et al. (2012) studied in-house two-phase fluid flow model by solving Navier-Stokes equations for cubic tank with different baffle configurations under the harmonic motion excitation [6]. Hasheminejed et al. (2014) studied two-dimensional transient sloshing in non-deformable baffled horizontal circular cylindrical vessels, filled with inviscid incompressible fluids to arbitrary depths, and subjected to arbitrary time-dependent lateral accelerations [9]. Babu et al. (2017) studied of sloshing impact on the tanker wall for different fluids with varying accelerations using VOF method for elliptical tanker. [5-8]. Otremba et al. (2018) studied more models to simulate the effects of the sloshing phenomenon on braking efficiency and the load transfer rate of a partially filled road tanker. They using CFD simulation.

\section{Materials and methods}

In this study the tanker is used to storage and transport agro-food liquid cargo under atmospheric pressure: crudes oil (sun-flower) and water for varying velocity $(14 \mathrm{~m} / \mathrm{s}, 20 \mathrm{~m} / \mathrm{s}$, $25 \mathrm{~m} / \mathrm{s})$ and for different fill levels $(40 \%, 80 \%)$. The tank model is presented in Figure1. It consists of a 3-dimensional fluids storage, with length $3840 \mathrm{~mm}$ and height $1300 \mathrm{~mm}$, with circular cross-section tank, and two baffles (height $1000 \mathrm{~mm}$ ). The study of influence of liquid motion on tank structure was using by FSI simulation in ANSYS Workbench simulation environment by using ANSYS CFX and Static Structural codes (static and transient). The geometrical design with advanced modeling techniques SolidWorks software is presented.in Figure 2. CFD model presented on Figure 3 was prepared by ANSYS mesh tool and consist of 21673 nodes, of tetrahedral cell elements 114915 .

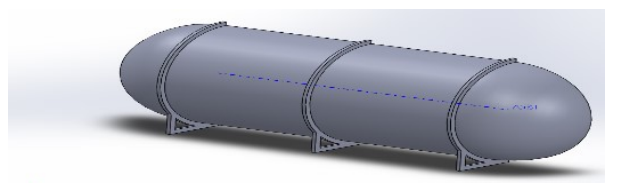

in

Fig.1.Physical model tanker

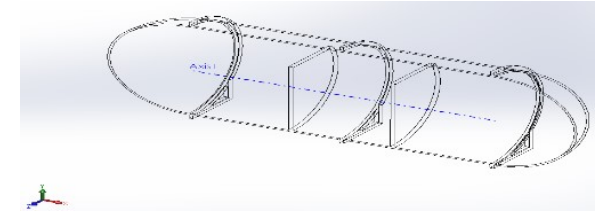

Fig.2. Geometrical design of the tanker 

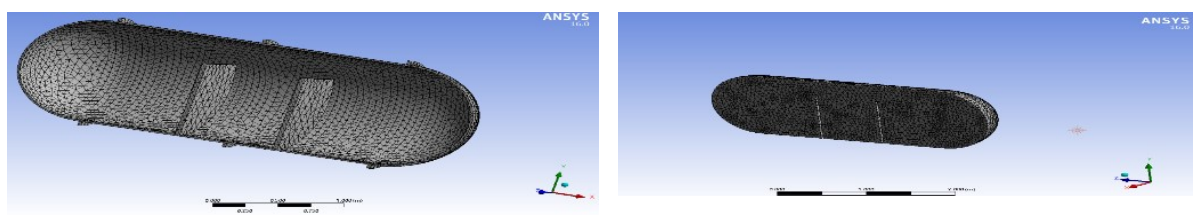

Fig.3. Mesh tanker and fluids

In this paper for both fluids it is studied the liquid behavior and simulated the modeled structure of the tank with the fill level of $80 \%$, at the imposed velocity that decreases at 14 $0 \mathrm{~m} / \mathrm{s}, 20-0 \mathrm{~m} / \mathrm{s}$ in $10 \mathrm{sec}$. And for the fill level of $40 \%$ at the imposed velocity that decreases at $25-0 \mathrm{~m} / \mathrm{s}$ in $10 \mathrm{sec}$. Thus in these cases the deceleration simulates a sudden braking and the stop of the tanker. The tanker accelerates for first $5 \mathrm{sec}$, such that the velocity goes up to $50 \mathrm{~km} / \mathrm{h}, 80 \mathrm{~km} / \mathrm{h}$ respectively, and last $5 \mathrm{sec}$ deceleration (braking). The properties the fluids like water and oil sun-flower are investigated to find the slosh impact over the wall are given in Table 1 .

Table 1.The specifications of the fluid agro-food simulation

\begin{tabular}{|r|c|c|c|l|}
\hline S.NO & NAME OF FLUID & NAME OF PROPERTY & VALUE & UNITS \\
\hline \multirow{2}{*}{1} & \multirow{2}{*}{ Water } & Density & 998.2 & $\mathrm{Kg} / \mathrm{m}^{3}$ \\
\cline { 3 - 5 } & & Viscosity & 0001003 & $\mathrm{Kg} / \mathrm{m}^{-1} \mathrm{~s}^{-1}$ \\
\hline \multirow{2}{*}{2} & \multirow{2}{*}{ Oil sun-flower } & Density & 920 & $\mathrm{Kg} / \mathrm{m}^{3}$ \\
\cline { 3 - 5 } & & Viscosity & 0004956 & $\mathrm{Kg} / \mathrm{m}^{-1} \mathrm{~S}^{-1}$ \\
\hline
\end{tabular}

Inside the tank there are two baffles mounted $0.8 \mathrm{~m}$ at a height of $1 \mathrm{~m}$ and thickness 3 $\mathrm{mm}$.

In present work, water and oil sun-flower fill level in tank is $40 \%$ and $80 \%$ of total height of tank and the rest part is occupied with air. The simulation with CFD is based on Volume Fraction (VOF) formulation when two or more fluids (or phases) don't penetrate each other. Having the following expression:

$$
\sum_{p=1}^{n} \alpha_{p}=1
$$

where : $\alpha_{\mathrm{p}}$ - volume fraction for those two fluids,

$\mathrm{n}$ - no of phases present in the computational cell,

p- fluids phase.

The value of $\alpha_{p}$ ranges between 0 to 1.0 represent the cell is empty, 1 represents the cell is full with the fluids $\mathrm{p}$. An intermediary value between 0 to 1 shows that there is an interface of one or more fluids.

VOF model can be analyzed from Figure 4. The red color represents the water and oil sun-flower phase, and the rest portion represents air from tanker. Having the following expression:

$$
\begin{gathered}
\alpha_{\text {water }}+\alpha_{\text {air }}=1 \\
\alpha_{\text {oil sun-flower }+} \alpha_{\text {air }}=1
\end{gathered}
$$

where : $\alpha_{\text {water }}$ - volume fraction for fluid phase (water),

$\alpha_{\text {oil sun-flower }}$ - volume fraction for fluid phase (sun-flower),

$\alpha_{\text {air }}$ - volume fraction for fluid phase (air).

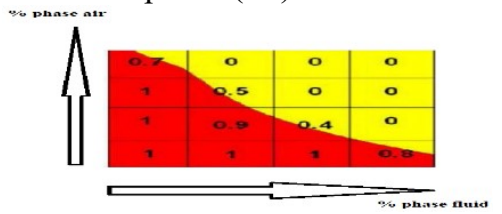

The fluid flow (water and oil sun-flower) during sloshing can be represented in the form of mathematical equations using continuity equations, the Navier-Stokes equations and turbulence modeling. 
Flow simulation for those two fluids agro-food (water and oil sun-flower) was conducted for the following conditions in ANSYS:

- liquids is water and oil sun-flower with properties at normal ambient temperature $\left(20^{\circ} \mathrm{C}\right)$; pressure based transient solver is used with explicit formulation and gravitational field is enabled;

- multiphase model with volume of fluid (VOF) method is used, and turbulent model is considered.

- flow is two phase (water and air, oil sun-flower and air respectively), homogenous with standard model of free surface and tank walls are ideal smooth with thickness $3 \mathrm{~mm}$;

- model is in thermal equilibrium, there is no heat exchange between fluids and environment and simulation is in transient conditions with acceleration peak $1 \mathrm{~g}$ in longitudinal direction;

- operating conditions: pressure $(101325 \mathrm{~Pa})$; gravitational acceleration: $\mathrm{g}_{\mathrm{x}}=0 \mathrm{~m} / \mathrm{s}^{2}$, $\mathrm{g}_{\mathrm{y}}=-9.81 \mathrm{~m} / \mathrm{s}^{2}, \mathrm{~g}_{\mathrm{z}}=0 \mathrm{~m} / \mathrm{s}^{2} ;$ density air $\left(1.225 \mathrm{~kg} / \mathrm{m}^{3}\right)$;

- non-iterative relaxation factor: pressure (0.8); momentum (0.6); turbulent kinetic energy: 1 ; turbulent dissipation rate: 1 .

- tanker material is carbon steel in according SR EN 10216-2 [10].

\section{Results and discussion}

In this chapter a sequence of numerical experiments carried out to estimate the pressure developed over the tanker wall and the free surface displacement of the fluids for different fill levels and velocity. Simulations with the two fluids and the results obtained are compared to be able to analyze the behavior of the tank partially filled into a braking maneuver.

In the first stage the simulations for all three velocities $(\mathrm{v}=14 \mathrm{~m} / \mathrm{s}, \mathrm{v}=20 \mathrm{~m} / \mathrm{s}, \mathrm{v}=25 \mathrm{~m} / \mathrm{s})$ were given, the tank being partially filled $80 \%(1 \mathrm{~m})$ with oil sun-flower. The simulation of the fluid being made only in the longitudinal direction gives the following pressures, and the behavior of the fluid in the tank can be seen in the Fig.5, 6 - a), b).
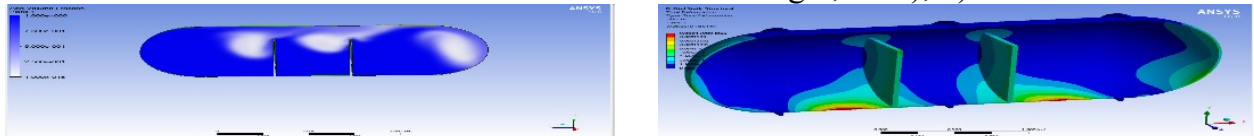

Fig.5. Behavior of the fluid in the tank when the speed is $v=14 \mathrm{~m} / \mathrm{s}$, time $10 \mathrm{~s}$, fill level $80 \%$, the color white is air, blue is oil sun-flower respectively

a)Sloshing liquid motion in tanker and volume fraction fluid; b) total deformation static

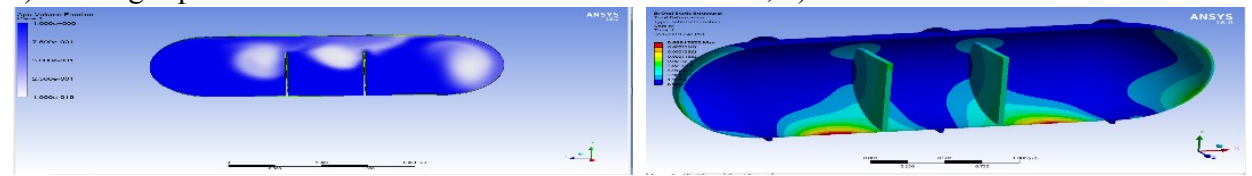

Fig.6. Behavior of the fluid in the tank when the speed is v $=20 \mathrm{~m} / \mathrm{s}$, time $10 \mathrm{~s}$, fill level $80 \%$, the color white is air, blue is oil sun-flower respectively

a) Sloshing liquid motion in tanker and volume fraction fluid; b) total deformation static structural carbon steel

Then simulation is repeated and for a filling level of $40 \%$ and velocity $\mathrm{v}=25 \mathrm{~m} / \mathrm{s}^{2}$ (Figure7 a), b)).
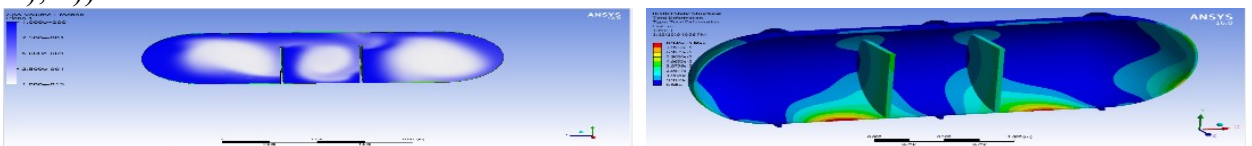

Fig.7. Behavior of the fluid in the tank when the speed is $v=25 \mathrm{~m} / \mathrm{s}$, time $10 \mathrm{~s}$, fill level $40 \%$, the color white is air, blue is sun-flower respectively

a)Sloshing liquid motion in tanker and volume fraction fluid; b) total deformation static structural carbon steel 
In the second part of the paper, the behavior of the tank with water for the three speeds is simulated, having a filling level of $80 \%(1 \mathrm{~m})$. Then for partially filled tank of $40 \%(0.55 \mathrm{~m})$. These simulation results are shown Fig.8, 9, $10-\mathrm{a})$, b).
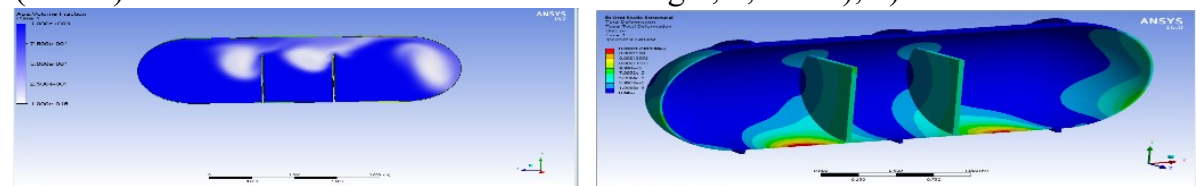

Fig.8. Behavior of the fluid in the tank when the speed is $v=14 \mathrm{~m} / \mathrm{s}$, time $10 \mathrm{~s}$, fill level $80 \%$, the color white is air, blue is water respectively

a) Sloshing liquid motion in tanker and volume fraction fluid; b) total deformation static structural carbon steel
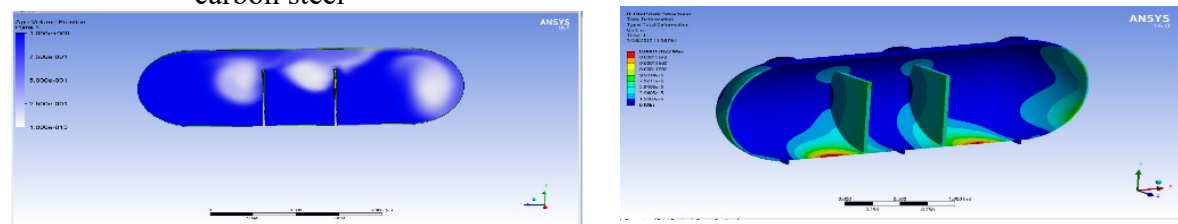

Fig.9. Behavior of the fluid in the tank when the speed is $v=20 \mathrm{~m} / \mathrm{s}$, time 10 s, fill level $80 \%$, the color white is air, blue is water respectively

a) Sloshing liquid motion in tanker and volume fraction fluid; b) total deformation static structural carbon steel
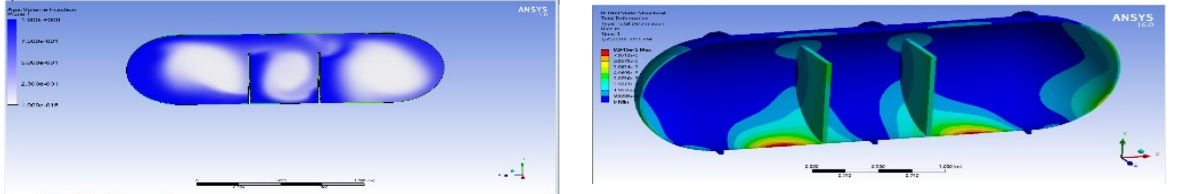

Fig.10. Behavior of the fluid in the tank when the speed is $v=25 \mathrm{~m} / \mathrm{s}$, time 10 s, fill level $40 \%$, the color white is air, blue is water respectively

a) Sloshing liquid motion in tanker and volume fraction fluid; b) total deformation structure carbon steel

The action of the pressures exercised by the two fluids (water and oil sun-flower) on the tank walls was analyzed both in static and transient structural for all speeds and filling levels.

Using FSI simulation could by highlighted the action and values of liquid velocity distributions, pressures, stress distribution $\left(10^{5} \mathrm{~Pa}\right)$ as well as the shape of the free surface shown in Fig.11 a),b) both for static structural as well transient structural.

Comparing these simulations, we can see that the stress distribution (equivalent stress von-Mises) is much higher when the tank is filled in $40 \%$ compared to $80 \%$ for varying velocity.
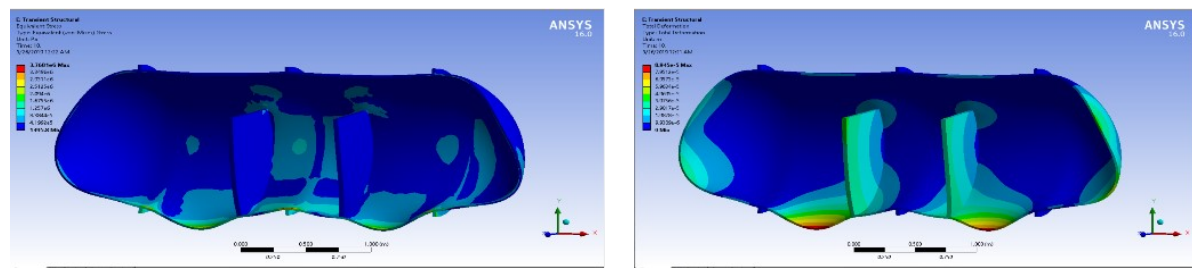

Fig.11. Using FSI simulation show the action and values of liquid velocity distributions, pressures, stress distribution

a) Equivalent stress in transient structural ; b) total deformation transient structural 


\section{Conclusion}

The study may be a starting point to make for an analysis looking and determining the dynamic behaviour of fluids agro-food in tanker during braking manoeuver.

By simulating with FSI simulation using ANSYS CFX and ANSYS Structural codes enable to obtain peak pressure value, deformation value respectively, under defined excitation and check its influence on tank structure and of the behaviour of fluids transported.

Through simulating different imposed speed and for different filling levels it has led to a better understanding and analysis of fluid behaviour inside a tanker with baffles.

By using baffles there has been a liquid stabilization and a good reduction in the sloshing effect.

The braking maneuver is highly dependent upon the fill volume, presence of baffles, and severity of braking input.

\section{References}

[1] D. Chaudhari, D. Deshmukh, Review on various roadways tanker cargo for controlling sloshing behavior, IJIRST, vol 2, pp. 80-85 (2014)

[2] M. Toumi et al., Impact of liquid sloshing on the vehicle tank design, Sciences \&Techn., n'28, pp. 29-34 (2008)

[3] M. Damagala, E. Lisowski, Interaction of liquid motion on mobile tank structure, JKPT, vol.18, pp.66-71 (2011)

[4] G. Kishore et al., Calculing Sloshing Impact on Tanker Walls for Fluids at Varying Acceleration, IJSR, vol.6, pp.785-795 (2015)

[5] R. Babu, R.K. Gotru, Study of Sloshing Impact on the Tanker Wall for Different Fluids with Varying Acceleration, IJIRST,vol.4, pp.10-16 (2017)

[6] P.K. Panigrahy, U.K. Saha, D. Maity, Experimental studies on sloshing behavior due to horizontal mouvement of liquids in baffled tanks, Oc. Eng., vol.36, pp.213-222 (2009)

[7] V. Singal, J. Bajaj, N. Awalgaonkar, S. Tibdewal, CFD Analysis of a Kerosene Fuel Tank to reduce liquid sloshing, Pro. Eng., vol.69, pp.1365-1371 (2014)

[8]D. Liu, P. Lin, Three-Dimensional liquid sloshing in a tank with baffles, Oc. Eng., vol.36, pp. 202-212 (2009)

[9] G. Brar, S. Singh, An Experimental and CFD Analysis of Sloshing in a Tanker, $2^{\text {nd }}$ ICIAME, pp.490-496 (2014)

[10] SR EN 10216-2 